\title{
Efeito do uso tópico do extrato aquoso de Orbignya phalerata (Babaçu) na cicatrização de feridas cutâneas - estudo controlado em ratos $^{1}$
}

\author{
Topic use of aqueous extract of Orbignya phalerata (babassu) in rats: analysis of it's healing \\ effect
}

\begin{abstract}
Elias Amorim², Jorge Eduardo F. Matias ${ }^{3}$, Júlio Cézar U. Coelho ${ }^{3}$, Antonio Carlos L. Campos ${ }^{3}$, Henrique Jorge Stahlke Jr ${ }^{3}$, Jorge Rufino Ribas Timi ${ }^{3}$, Luiz Carlos de Almeida Rocha ${ }^{3}$, Ana Tereza Ramos Moreira ${ }^{3}$, Daniel Zeni Rispoli $^{4}$, Lydia Masako Ferreira ${ }^{3}$
\end{abstract}

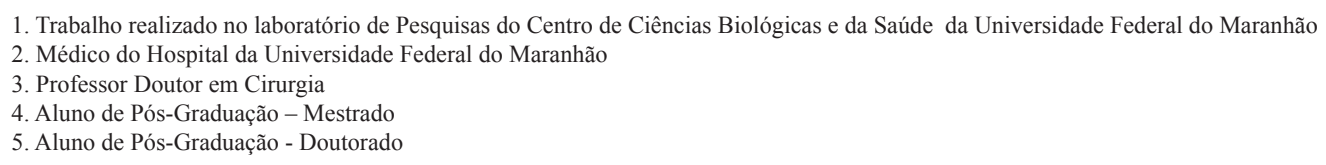

\section{RESUMO}

Introdução: O mesocarpo de Orbignya phalerata tem sido usado em estudos experimentais procurando verificar sua ação pró-inflamatória. Objetivo: Analisar comparativamente as alterações histológicas proporcionadas pelo extrato aquoso do Babaçu nas feridas cutâneas. Métodos: Sessenta ratos da linhagem Wistar, adultos, machos, foram utilizados. O procedimento experimental constituiu-se em uma incisão circular de $2 \mathrm{~cm}$ de diâmetro na pele com punch metálico. Após este procedimento comum a todos, os animais foram distribuídos aleatoriamente em dois grupos contendo 30 animais cada. No grupo controle não foi utilizada a substância pesquisada e sim, solução fisiológica (Cloreto de sódio a 0,9\%). No grupo experimento utilizou-se solução aquosa de Orbignya phalerata em uso tópico. Os animais foram acompanhados e mortos em sete, 14 e 21 dias. Foi feita análise histológica comparativa entre os grupos. Resultados: Observou-se diferença significativa a favor da cicatrização do grupo experimento em relação ao grupo controle nos $7^{\circ}$ e $14^{\circ}$ dias, no que diz respeito à reepitelização. Conclusão: O uso tópico do mesocarpo de Orbignya phalerata (Babassu) contribuiu positivamente para a cicatrização das feridas cutâneas em ratos com a dosagem de $25 \mathrm{mg} / \mathrm{ml}$.

Descritores: Orbignya phalerata. Cicatrização de Feridas. Pele. Ratos.

\begin{abstract}
Introduction: The mesocarp of Babassu (Orbignya phalerata) has been used in experimental studies trying to check its pro-inflammatory effect. Purpose: To analyse comparatively the histological changes made by the water extract of Babassu in skin surgical wounds. Methods: Sixty Wistar adults male rats were used. The experimental procedure was a circle skin incision of $2 \mathrm{~cm}$ in diameter made with a metal punch. After this procedure done in all animals, they were randomized in two groups of 30. In the control group, the phytotherapic agent wasn't used but saline solutin. In the experimental group, the water extract of Orbignya phalerata was used in the cut sites. All animals were followed and killed after seven, 14 and 21 days. Comparative histological analysis was made among the groups. Results: In the microscopic view, a significant reepitelization effect on the healing process of the experimental group in relation to the control group in the $7^{\text {th }}$ and $14^{\text {th }}$ days, was recognized. Conclusion: The use of the mesocarp of Orbignya phalerata in skin surgical wounds contributed positively in the healing process in rats.
\end{abstract}

Key words: Orbignya phalerata. Wound Healing. Skin. Rats.

\section{Introdução}

A capacidade de reparação tecidual é fenômeno observado nos seres vivos e de grande importância para sua sobrevivência quando ocorrem lesões acidentais ou cirúrgicas.

A cicatrização dos tecidos e órgãos constitui-se em um processo biológico complexo essencial para manter a integridade do organismo, mas que ainda não está totalmente esclarecido.

Ao longo dos séculos, procurou-se verificar a ação de substâncias químicas e/ou de procedimentos que pudessem agilizar o processo, quer na ferida limpa, quer na contaminada ou infectada ${ }^{1}$. Contudo alguns deles mostraram-se in- eficientes ou mesmo atuantes no retardamento da cura.

A cicatrização de uma ferida cirúrgica ou do sítio cirúrgico incisional apresenta aspectos químicos, físicos ou biológicos que ocorrem logo após a lesão tecidual e que difere nas feridas abertas e fechadas. A manipulação delas, objetivando melhores resultados cicatriciais, desafiou os cirurgiões que criaram alternativas melhorando vagarosamente todo o processo ao longo dos séculos ${ }^{2,3,4,5}$.

Com o uso de novas técnicas operatórias e de medicamentos sistêmicos ou tópicos, ocorreram modificações que 
promoveram melhor conhecimento sobre o mecanismo da cura e suas fases.

Iniciam-se elas no processo de inflamação (substituição de células mortas e/ou danificadas por células saudáveis), seguindo-se pela regeneração (substituição por células do mesmo tipo) e reparação por tecido conjuntivo (cica-

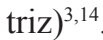

Assim, segundo Félix ${ }^{4,6}$, a cicatrização é dividida em três fases fundamentais: inflamatória (três a quatro dias), proliferativa (três a quatro semanas) e maturação (a partir de então).

$\mathrm{Na}$ fase inflamatória, ocorrem fenômenos vasculares e químicos, destacando-se o aumento da permeabilidade vascular, causado pela liberação local de histamina e serotonina, que atuam por cerca de 30 minutos sobre vênulas. Segue-se a formação de bradicinina e prostagladina, a partir de globulinas plasmáticas, que levam à prorrogação do processo e permite a chegada de granulócitos e monócitos. Os primeiros desempenham importante papel na remoção de resíduos celulares no local da lesão.

$\mathrm{Na}$ fase proliferativa, a lesão é recoberta por tecido epitelial. É nesta fase que aparecem os fibroblastos (terceiro dia), cuja origem é discutida. Eles têm participação muito importante, pois apresentam intensa capacidade de síntese protéica e multiplicação celular, produzindo substância fundamental (mucopolissacarídeos, glico e mucoproteínas) e colágeno. Ocorre proliferação de capilares a partir de resíduos venulares. As células endoteliais, à medida que se multiplicam, atraem-se tendendo a formar vasos.

Na última fase, a maturação, na medida que o colágeno vai sendo produzido, ocorre a oclusão da ferida, os capilares se organizam, os fibroblastos diminuem em número e observa-se queda da produção de substância fundamental.

Cumpre, entanto, salientar que tais fases da cicatrização não constituem processos isolados, mas apresentam dinamismo visível, que, com freqüência, sobrepõe-se uns aos outros, de tal sorte que, numa mesma fase, podem-se encontrar os elementos que compõem as subseqüentes.

O conhecimento da intimidade de cada uma das fases é fundamental para poder-se interferir positivamente no processo.

A utilização de plantas na prevenção e cura de doenças é muito antiga e data dos primórdios da civilização e muitas foram ou ainda são usadas nas feridas ${ }^{7}$.

Visando garantir a qualidade dos produtos fitoterápicos, desde a matéria-prima até o produto acabado para assegurar ao consumidor produtos padronizados em condições apropriadas para o uso, o Ministério da Saúde do Brasil, por intermédio da Secretaria de Vigilância Sanitária, publicou a Portaria $n^{\circ} 06$ de 31 de janeiro de 1995. Ela instituiu e normalizou no país tanto o registro de fitoterápico, quanto a regulamentação dos procedimentos de sua produção. Possibilitou ainda, o uso de fitoterápicos marcadores-constituintes quimicamente definidos, presentes na matéria-prima vegetal, preferencialmente os próprios princípios ativos ${ }^{8}$.

Apesar da transferência de conhecimento de uma geração para a outra, a maior parte dela é fundamentada no empirismo. É importante enfatizar que algumas plantas utilizadas pela população de fato apresentam propriedades terapêuticas, mas também, outras existem que causam grande toxicidade. Este fato torna o uso indiscriminado de fitoterápicos um risco ${ }^{9}$.

Freqüente entre nós, e de grande importância econômica, situa-se o Babaçu9 ${ }^{9}$ O mesocarpo da fruta é rico em carbohidratos e sais minerais, e possui atividades antiinflamatórias ${ }^{6,12}$. Esta planta da família palmae, é nativa do meio-norte do Brasil e encontrada com maior freqüência no Estado do Maranhão. É uma palmeira e forma a floresta dos cocais $^{13}$. Sua área de ocorrência é a zona de transição entre as florestas úmidas da bacia amazônica e as terras semi-áridas do nordeste brasileiro ${ }^{10,11,12}$.

Existem muitas informações na crendice popular acerca do seu uso como medicamento, entre elas, cita-se o poder de cicatrização, que carece de informação científica para sua comprovação.

Existem muitas dúvidas e uma grande quantidade de trabalhos controversos. Assim, há necessidade de procurar-se comprovação científica para validar o dito popular, e esta é uma das razões do porquê este trabalho foi idealizado.

Assim, o objetivo deste estudo é analisar comparativamente através da planimetria, macroscopia e microscopia, qual é o efeito do extrato aquoso do mesocarpo da Orbignya phalerata (Babaçu), proporcionadas as feridas cutâneas experimentais.

\section{Métodos}

Este trabalho foi realizado no Laboratório de Pesquisa do Departamento de Fisiologia e Farmacologia do Centro de Ciências Biológicas e da Saúde da Universidade Federal do Maranhão - UFMA. Foram adotadas os Princípios Éticos em Experimentação Animal, preconizados pelo Colégio Brasileiro de Experimentação Animal (COBEA), instituição filiada ao International Council for Laboratory Animal Science e a Legislação Brasileira de Animais de Experimentação, Lei Federal n. ${ }^{\circ} 6.638$ (1979).

$\mathrm{O}$ projeto da pesquisa foi submetido à apreciação e aprovação do Comitê de Ética em Pesquisa (CEP) do Hospital Universitário Presidente Dutra - HUPD da Universidade Federal do Maranhão - UFMA.

\section{Amostra e identificação dos animais}

Foram estudados 60 ratos (Rattus novergicus albinus, Rodentia mammalia), da linhagem Wistar, adultos, machos, com idade média de 45 dias pesando entre 129 a 234 gramas, adquiridos no Biotério Central de Campinas, São Paulo (UNICAMP), Centro Multidisciplinar para Investigação Biológica (CEMIB) e transferidos para o Laboratório de Pesquisa do Departamento de Fisiologia e Farmacologia do Centro de Ciências Biológicas e da Saúde da Universidade Federal do Maranhão.

Eles permaneceram em gaiolas plásticas padrão sendo cinco animais em cada gaiola, mantidos em temperatura e umidade naturais do ambiente, com livre acesso a água e ração de origem industrial (Purina ${ }^{\circledR}$ - Labina) em ciclo circadiano (claro/escuro), forradas com serragem de pinho. Instituiu-se período de aclimatação durante sete dias. 
Os animais foram distribuídos de forma aleatória em dois grupos de 30, sendo o Grupo I (de 1 a 30) definido como Grupo Controle (GC) e o Grupo II (de 31 a 60) como Grupo de Experimentação (GE). Foram pesados e identificados em grupos com ácido pícrico. Cada gaiola foi identificada com o grupo que o animal pertencia e data da operação.

\section{Preparo do extrato de Orbignya phalerata}

O mesocarpo do Babaçu foi obtido do coco maduro. A coleta foi feita quando estavam no chão caídos naturalmente dos cachos.

A retirada do mesocarpo de Babaçu foi feita na área do Campus Universitário do Bacanga, localizado na Avenida dos Portugueses s/n, São Luís-MA no mês de agosto de 2002. A planta está catalogada sob o número 1136 no Herbário Ática Seabra na Universidade Federal do Maranhão - UFMA.

Para extração do mesocarpo do coco, utilizou-se um bastão de madeira batendo-se manualmente na parte superior até ruptura das cascas e em seguida, com auxílio de uma espátula, separou-se o mesocarpo. O material obtido foi posto sobre uma bancada durante três dias. Depois de seco foi colocado em estufa de secagem na temperatura de $45-50^{\circ} \mathrm{C}$ durante $24 \mathrm{~h}$ para retirada total da umidade. $\mathrm{O}$ mesocarpo foi submetido ao processo de moagem em moinho elétrico do Laboratório do Pavilhão Tecnológico da Universidade Federal do Maranhão - UFMA, onde se obteve o pó em forma de farinha.

Para a preparação do extrato aquoso, pesou-se o pó e diluiu-se em solução salina para uma concentração de $25 \mathrm{mg} / \mathrm{mL}$.

\section{O experimento}

Os animais tiveram a ração suspensa por quatro horas antes dos procedimentos cirúrgicos, porém permaneceram com ingestão de água ad libitum.

Os procedimentos de indução anestésica foram realizados em campânula de plástico fechada, contendo algodão hidrófilo umedecido com éter etílico até ficar com nenhum movimento, desaparecimento dos reflexos palpebrais e ritmo respiratório constante.

Atingido o plano anestésico, cada animal foi colocado sobre prancha cirúrgica, em decúbito ventral e imobilizado por fita elástica. Foram mantidos em nível anestésico com inalação intermitente em sistema de máscara artesanal confeccionado com seringa de $60 \mathrm{~mL}$ sem o êmbulo, contendo algodão embebido em éter etílico, ficando o segmento cefálico do animal parcialmente no interior da seringa (Figura 1).

A técnica operatória, após a epilação, seguiu a mesma padronização para os animais de ambos os grupos. Consistiu em excisão total da pele com $2 \mathrm{~cm}$ de diâmetro no centro da área epilada realizada com um punch metálico cortante (Figuras 2 e 3), preparado para esse fim e semelhante aos utilizados em cirurgia plástica. A hemostasia foi feita por compressão digital com gases.

Os animais do Grupo I receberam soro fisiológico no curativo diário, enquanto os do Grupo II extrato aquoso da

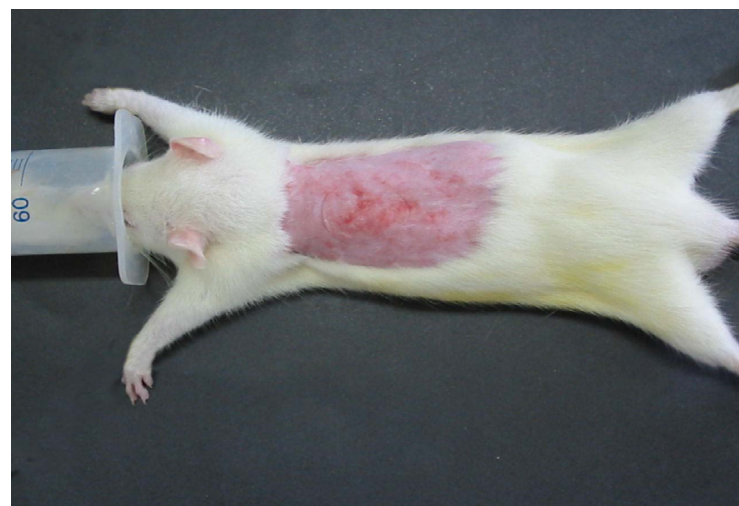

FIGURA 1 - Área epilada e aspecto da manutenção da anestesia. Nota : 1. Observar o detalhe da cabeça do animal dentro da seringa que contém o éter para manter a anestesia. 2.Observar o detalhe da marcação com ácido pícrico no membro posterior

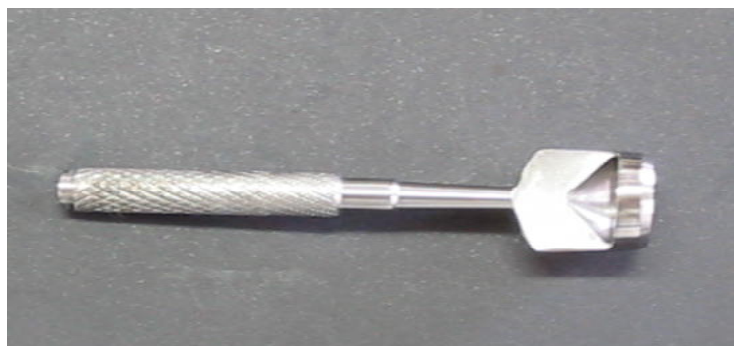

FIGURA 2 - Punch metálico para excisão cutânea. Nota: Observar a extremidade circular cortante do instrumento para demarcação da área a ser seccionada.

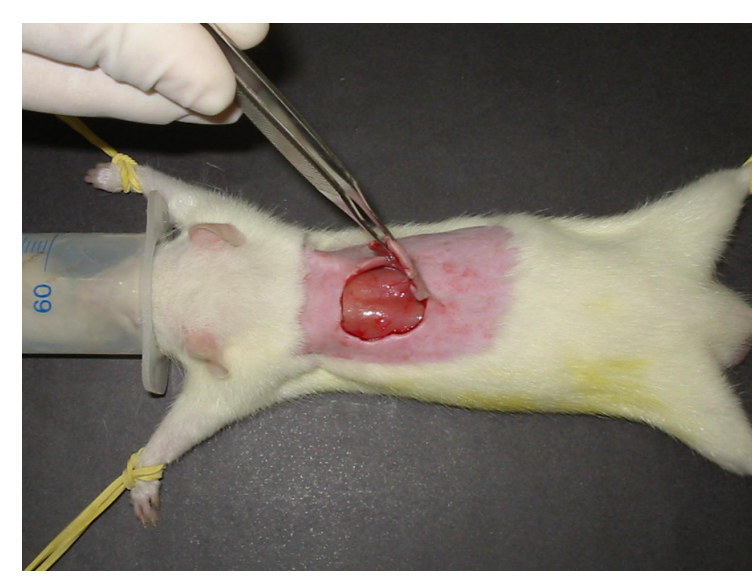

FIGURA 3 - Excisão da pele. Nota: Observar o detalhe da área demarcada pelo punch e seccionada respeitando-se o plano muscular.

Orbignya phalerata em uso tópico através de seringa de $1 \mathrm{ml}$ com dose de $0,1 \mathrm{~mL}$, durante sete, 14 ou 21 dias consecutivos a partir da operação, e sacrificados nesses dias.

Ao final do procedimento os animais foram recolocados 
nas suas respectivas gaiolas do mesmo modo que no período pré-operatório. Receberam alimentação imediata. Foram examinados diariamente, anotando-se as condições da ferida e suas complicações nas fichas-protocolo.

A aplicação pós-operatória do extrato aquoso do Babaçu foi feita manualmente, com o produto sendo retirado do refrigerador e homogeneizado manualmente na hora da aplicação de $10 \mathrm{~mL}$ com seringa sem agulha nas feridas dos animais do grupo experimento, diariamente, até o dia anterior a morte de acordo com a data estabelecida para cada grupo. Para a instilação do fitoterápico, os animais eram contidos manualmente sobre a tampa da gaiola.

Também foram realizadas medidas da ferida no $7^{\circ}, 14^{\circ}$ e $21^{\circ}$ dias de observação com paquímetro digital.

Antes da morte, os animais foram novamente pesados e colocados individualmente na campânula de vidro contendo dose inalatória letal de éter etílico até que ocorresse o óbito.

\section{Avaliação macroscópica}

Com auxílio de uma lupa com 2,5 vezes de aumento e os animais fixados à mesa cirúrgica, foram medidos os tamanhos das lesões, no maior e no menor diâmetros, utilizando-se um paquímetro digital (Figura 4) para comparação com a medida inicial padronizada em $2 \mathrm{~cm}$. Neste tempo, foi feito o registro fotográfico digital com câmera fixada em tripé à distância padrão de $34 \mathrm{~cm}$ do objeto e a seguir a planimetria digital (Figura 4).

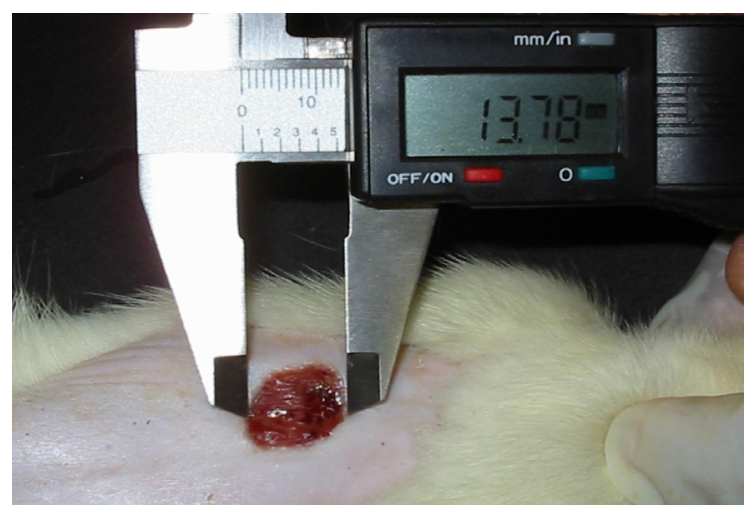

FIGURA 4 - Medição da ferida com o paquímetro digital

A imagem da fotografia digital da lesão, foi importada para o software Auto Cad 14 e, após a delimitação da periferia pelo método poliline (demarcação de todos os pontos da lesão), foi feito o cálculo da área tendo como referência a medida do maior diâmetro realizada com o paquímetro digital, para então transformá-lo em medida decimal (Figura 5).

Em cada observação verificava-se a presença de crostas, secreções e cicatriz hipertrófica. Para análise, o material foi retirado com margem de $1 \mathrm{~cm}$ de pele em torno da lesão,

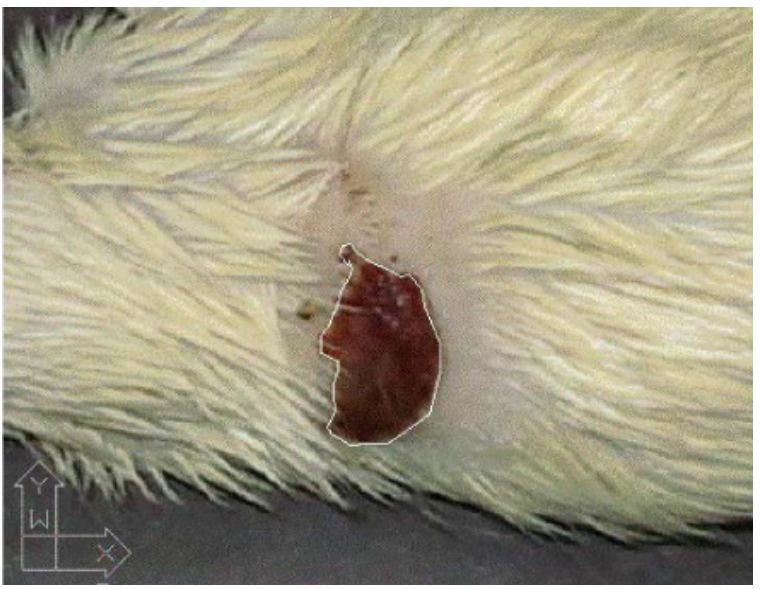

FIGURA 5 - Delimitação da lesão pelo método poliline

identificado, colocado em solução de formol a 10\%, fixado aberto em isopor e encaminhado ao Laboratório de Patologia do Hospital Universitário Presidente Dutra, onde foram confeccionadas as lâminas para avaliação histológica.

\section{Avaliação microscópica}

As peças foram submetidas coloração com hematoxilina-eosina (H-E) e tricômio de Masson e avaliadas quanto à proliferação vascular, presença de células mononucleares e polimorfonucleares, proliferação de fibroblastos, presença de colágeno e reepitelização na área de cicatrização.

\section{Análise estatística}

Os dados foram analisados utilizando-se o programa Statistics for Windows 5.1. Os efeitos no $7^{\circ}, 14^{\circ}$ e $21^{\circ}$ dias em ambos os grupos nas variáveis numéricas (peso, raio maior, raio menor e dimensão da área), foram calculados pelo teste da ANOVA com dois fatores de interação entre si. Essas mesmas variáveis foram analisadas pelo teste $t$ para avaliação somente do efeito do grupo. As variáveis da avaliação microscópica e macroscópica foram analisadas pelo teste não-paramétrico de Mann-Whitney. O nível de significância (p) utilizado para se rejeitar a hipótese da nulidade foi de 0,05 .

\section{Resultados}

Nenhum animal do grupo experimento de sete dias apresentava secreção purulenta na ferida, porém, ela foi observada em um do grupo controle desse dia. Observou-se também presença de crostas espessas em quatro animais do grupo experimento de sete dias e em dois dos controles.

No grupo de 14 dias, os animais do experimento apresentaram ferida limpa e sem presença de secreção purulenta e observou-se que em um a ferida já estava cicatrizada. Em relação ao grupo controle, nenhuma ferida estava cicatrizada nesse período.

Em 21 dias, tanto no grupo controle quanto no experimento, todas as feridas estavam cicatrizadas. 
A imagem analisada por planimetria digital mostra decréscimo considerável no tamanho da lesão de sete dias em relação ao de 14 e cicatrização total em 21 dias. Analisando-se isoladamente cada etapa, no grupo experimento de sete dias, observou-se que a área variou entre 0,2958 a 1,5475 com média de 0,86911 . No grupo controle, a área variou de 0,7367 a 2,1371 com média de 1,46928 mostrando efeito positivo da substância utilizada no grupo experimento (Tabela 1).

TABELA 1 - Planimetria do grupo experimento e controle de 7 dias.

\begin{tabular}{cccc}
\hline \multicolumn{2}{c}{ Experimento } & \multicolumn{2}{c}{ Controle } \\
\hline Rato & Área & Rato & Área \\
\hline 1 & 0,7742 & 1 & 1,3873 \\
2 & 0,7755 & 2 & 1,7583 \\
3 & 0,2958 & 3 & 1,1865 \\
4 & 0,9247 & 4 & 1,5727 \\
5 & 1,0659 & 5 & 0,7367 \\
6 & 1,0334 & 6 & 1,3643 \\
7 & 1,5475 & 7 & 1,2706 \\
8 & 1,214 & 8 & 2,1371 \\
9 & 0,594 & 9 & 1,5454 \\
10 & 0,4661 & 10 & 1,7339 \\
Média & 0,86911 & Média & 1,46928 \\
\hline
\end{tabular}

$\mathrm{Na}$ análise do grupo experimento de 14 dias, a área variou entre 0 e 0,03815 com média de 0,18729 . No grupo controle, variou de 0,0012 a 0,3345 com média de 0,09868 confirmando que nesta fase o grupo experimento confirma o efeito positivo (Tabela 2).

TABELA 2 - Planimetria do grupo experimento e controle de 14 dias

\begin{tabular}{cccc}
\hline \multicolumn{2}{c}{ Experimento } & \multicolumn{2}{c}{ Controle } \\
\hline Rato & Área & Rato & Área \\
\hline 1 & 0,141 & 1 & 0,01 \\
2 & 0 & 2 & 0,0012 \\
3 & 0,0191 & 3 & 0,053 \\
4 & 0,26 & 4 & 0,1315 \\
5 & 0,2862 & 5 & 0,0797 \\
6 & 0,2651 & 6 & 0,2034 \\
7 & 0,1163 & 7 & 0,3345 \\
8 & 0,2926 & 8 & 0,1164 \\
9 & 0,1111 & 9 & 0,0386 \\
10 & 0,3815 & 10 & 0,0185 \\
Média & 0,18729 & Média & 0,09868 \\
\hline
\end{tabular}

No grupo de 21 dias, a área tanto do grupo experimento quanto do grupo controle estavam totalmente cicatrizadas (Tabela 3).

A Tabela 4 mostra que houve diferença significativa nas médias de sete dias em relação a 14 e 21 dias verificadas
TABELA 3 - Planimetria do grupo experimento e controle de 21 dias

\begin{tabular}{cccc}
\hline \multicolumn{2}{c}{ Experimento 21 Dias } & \multicolumn{2}{c}{ Controle 21 Dias } \\
\hline Rato & Área & Rato & Área \\
\hline 1 & 0 & 1 & 0 \\
2 & 0 & 2 & 0 \\
3 & 0 & 3 & 0 \\
4 & 0 & 4 & 0 \\
5 & 0 & 5 & 0 \\
6 & 0 & 6 & 0 \\
7 & 0 & 7 & 0 \\
8 & 0 & 8 & 0 \\
9 & 0 & 9 & 0 \\
10 & 0 & 10 & 0 \\
Média & 0 & Média & 0 \\
\hline
\end{tabular}

TABELA 4 - ANOVA com dois fatores de interação da variável área

\begin{tabular}{lllll}
\hline FV & GL & QM & F & p \\
\hline Dias - D & 2 & 8,1201 & 158,4691 & 0,0000 \\
Grupo - G & 1 & 0,4303 & 8,3974 & 0,0054 \\
D x G & 2 & 0,7050 & 13,7589 & 0,0000 \\
Resíduo & 54 & 0,0512 & & \\
\hline
\end{tabular}

em favor do grupo experimento comparado com o grupo controle.

A Tabela 5 mostra que a média de sete dias foi maior que as de 14 e 21 dias, ou seja, que a partir de 14 dias houve redução da área da ferida do grupo experimento. Comparando as médias de sete dias com as de 14 e 21 dias, houve significância estatística, enquanto que entre 14 e 21 dias ela não ocorreu.

TABELA 5 - Teste de Tuckey para comparação de médias dos dias.

\begin{tabular}{lcc}
\hline Dias & \multicolumn{1}{c}{ Área $\left(\mathbf{c m}^{2}\right)$} \\
\hline $\mathbf{7}$ & $1,1692^{\mathrm{a}}$ \\
& $\mathbf{1 4}$ & $0,1430^{\mathrm{b}}$ \\
$\mathbf{2 1}$ & $0,0017^{\mathrm{b}}$ \\
\hline
\end{tabular}

Nota: As letras diferentes quando comparadas entre si significam que $\mathrm{p}<0,05$

A Tabela 6 mostra que houve diferença significativa na diminuição da área do grupo experimento em relação ao grupo controle.

TABELA 6 - Teste de Tuckey para comparação de médias dos grupos.

\begin{tabular}{cc}
\hline Grupos & Média $\left(\mathbf{c m}^{2}\right)$ \\
\hline Controle & $0,5226^{\mathrm{a}}$ \\
Experimento & $0,3533^{\mathrm{b}}$ \\
\hline
\end{tabular}

Nota: As letras diferentes quando comparadas entre si significam que $\mathrm{p}<0,05$ 
A Figura 6 mostra diferença significativa da área do $7^{\circ}$ ao $14^{\circ}$ dia que reduziu $1.2 \mathrm{~cm}$ para $0.2 \mathrm{~cm}$ e diferença mínima em relação ao $21^{\circ}$ dia que reduziu de $0.2 \mathrm{~cm}$ para 0.

A Figura 7 mostra que a média da área do grupo experimento é menor que a área do grupo controle com resultado significante estatisticamente em favor do grupo experimento.

A Figura 8 mostra que a principal diferença foi no $7^{\circ}$ dia em que o grupo controle tinha área maior que o grupo experimento e no $14^{\circ}$ e $21^{\circ}$ dias não houve diferença significativa.

\section{Análise microscópica}

Quanto à análise microscópica, houve diferença significativa nas variáveis mononucleares e reepitelização entre os vários períodos de tempo.

A Tabela 7 mostra que a presença de células mono- nucleares foi mais intensa no grupo controle que no grupo experimento e apresentou significância estatística, observando-se ainda que a reepitelização foi mais evidente no grupo experimento que no controle apresentando significância estatística (Figuras 9 e 10)

Na Tabela 8 do grupo de 14 dias observa-se que apenas a variante mononucleares apresentou significância estatística, com o grupo experimento sendo mais evidente (Figuras 11 e 12).

Na Tabela 9 observando-se os dois grupos aos 21 dias, não se vê significância estatística entre eles, porém, a presença de fibras colágenas foi ligeiramente maior no grupo experimento, enquanto a variante reepitelização foi um pouco maior no grupo controle (Figuras 13 e 14).

Quanto à análise microscópica, houve diferença significativa nas variáveis mononucleares e reepitelização a favor do grupo experimento. No $14^{\circ}$ dia somente a variável mononuclear apresentou diferença significativa.

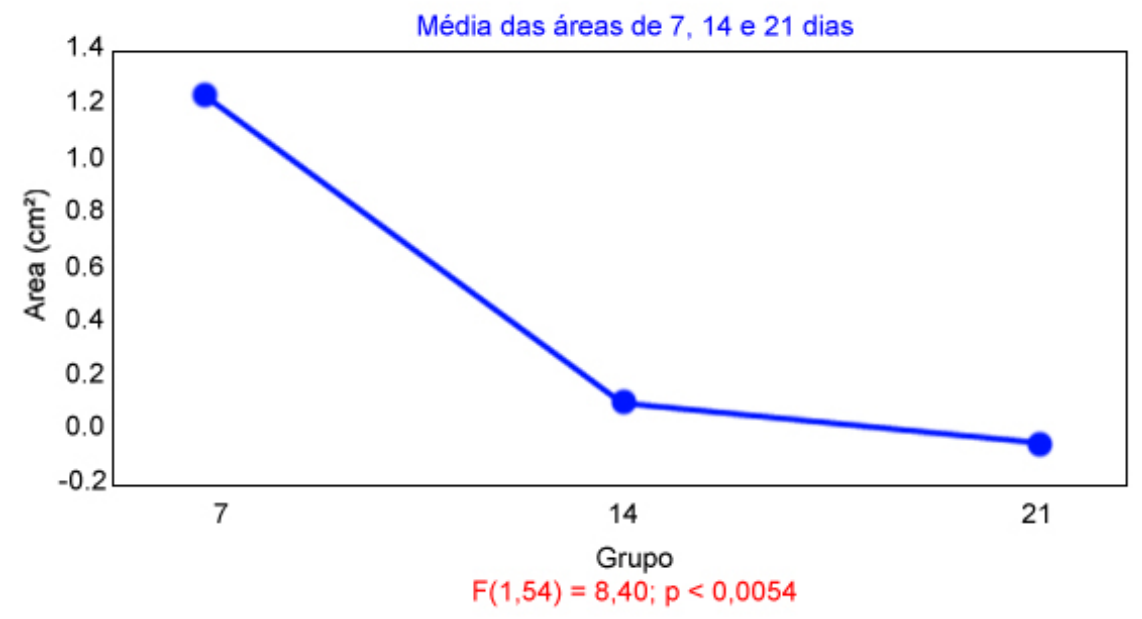

FIGURA 6 - Média das áreas de 7,14 e 21 dias. Legenda: F= Significância da interação, p= Nível de significância.

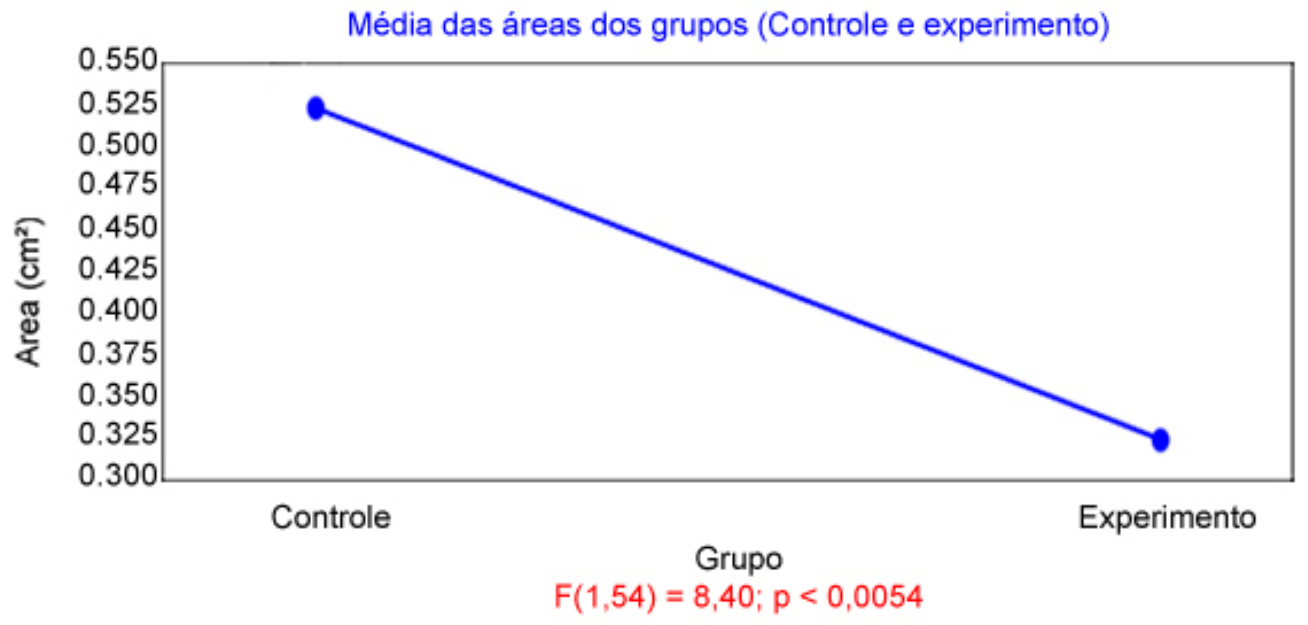

FIGURA 7 - Média das áreas dos grupos (Controle e Experimento). Legenda : F= Significância da Interação, p= Nível de Significância. 


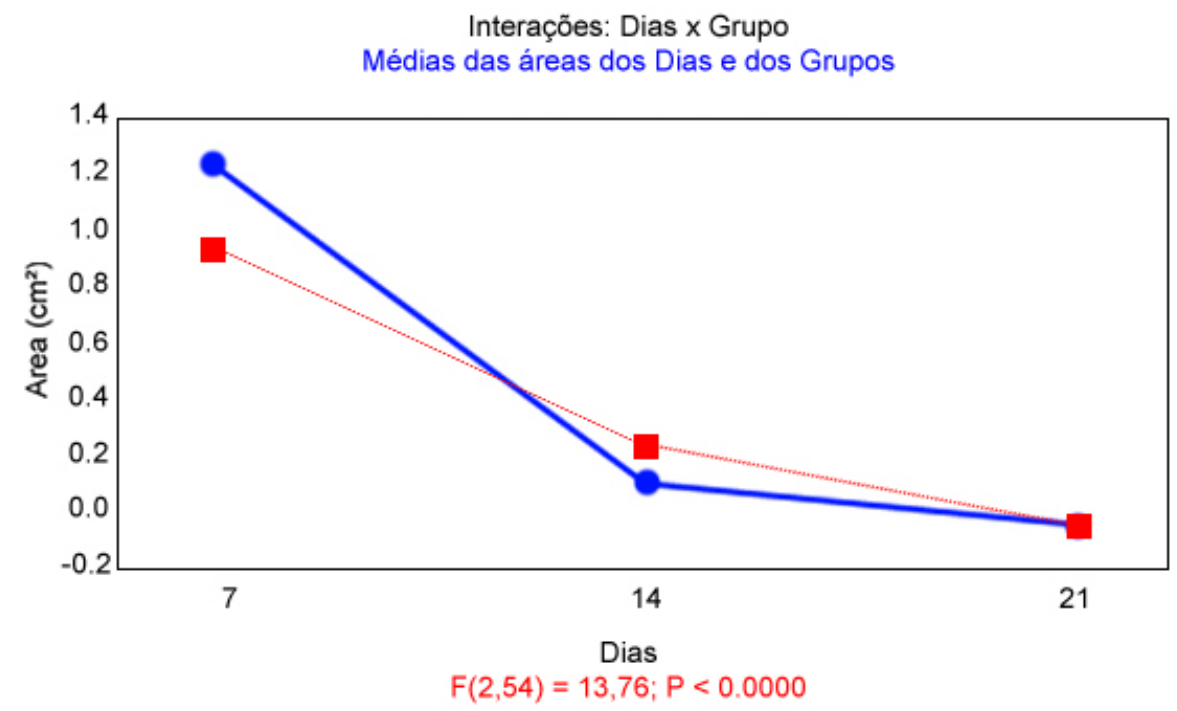

FIGURA 8 - Interação entre dias e grupos média das áreas dos Dias e dos Grupos. Legenda: F= Significância da interação, $p=$ Nível de significância

TABELA 7 - Teste não paramétrico de Mann-Whitney para as variáveis da análise histológica do $7^{\circ}$ dia

\begin{tabular}{lcccc}
\hline & Controle & Experimento & $\mathbf{Z}$ & $\mathbf{p}$ \\
\hline Proliferação Vascular & 115 & 95 & 0,756 & 0,450 \\
Mononucleares & 131 & 79 & 1,965 & $0,049^{*}$ \\
Polimorfonucleares & 109,5 & 100,5 & 0,340 & 0,734 \\
Proliferação de Fibroblastos & 84,5 & 125,5 & $-1,550$ & 0,121 \\
Fibras Colágenas & 120 & 90 & 1,134 & 0,257 \\
Reepitelização & $\mathbf{7 5}$ & $\mathbf{1 3 5}$ & $\mathbf{- 2 , 2 6 8}$ & $0,023^{*}$ \\
\hline
\end{tabular}

TABELA 8 - Teste não paramétrico de Mann-Whitney para as variáveis da análise histológica do $14^{\circ}$ dia

\begin{tabular}{lcccc}
\hline & Controle & Experimento & $\mathbf{Z}$ & $\mathbf{p}$ \\
\hline Proliferação Vascular & 95 & 115 & $-0,756$ & 0,450 \\
Mononucleares & 75 & 135 & $-2,268$ & $0,023^{*}$ \\
Polimorfonucleares & 107 & 103 & 0,151 & 0,880 \\
Proliferação de Fibroblastos & 130 & 80 & 1,890 & 0,059 \\
Fibras Colágenas & 110 & 100 & 0,378 & 0,705 \\
Reepitelização & 115 & 95 & 0,756 & 0,450 \\
\hline
\end{tabular}

TABELA 9 - Teste não paramétrico de Mann-Whitney para as variáveis da análise histológica do $21^{\circ}$ dia

\begin{tabular}{lcccc}
\hline & Controle & Experimento & $\mathbf{Z}$ & $\mathbf{p}$ \\
\hline Proliferação Vascular & 100 & 110 & -0.378 & 0.705 \\
Mononucleares & 85 & 125 & -1.512 & 0.131 \\
Polimorfonucleares & 105 & 105 & 0.000 & 1.000 \\
Proliferação de Fibroblastos & 105 & 105 & 0.000 & 1.000 \\
Fibras Colágenas & 96 & 114 & -0.680 & 0.496 \\
Reepitelização & 110 & 100 & 0.378 & 0.705 \\
\hline
\end{tabular}

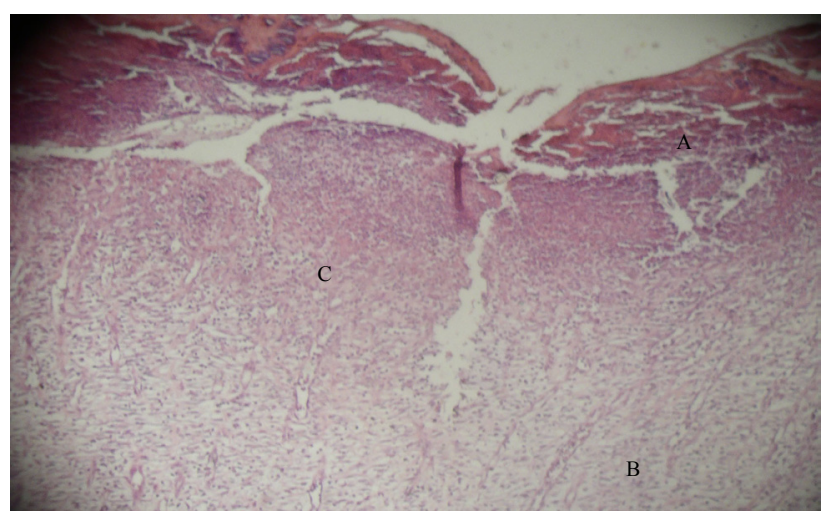

FIGURA 9 - Fotomicrografia do grupo experimento do $7^{\circ}$ dia. Nota: Figura mostra a ausência de epitélio (A), presença de vasos com neoformação (B) e de polimorfonucleares (C) (H-E com aumento de 10x

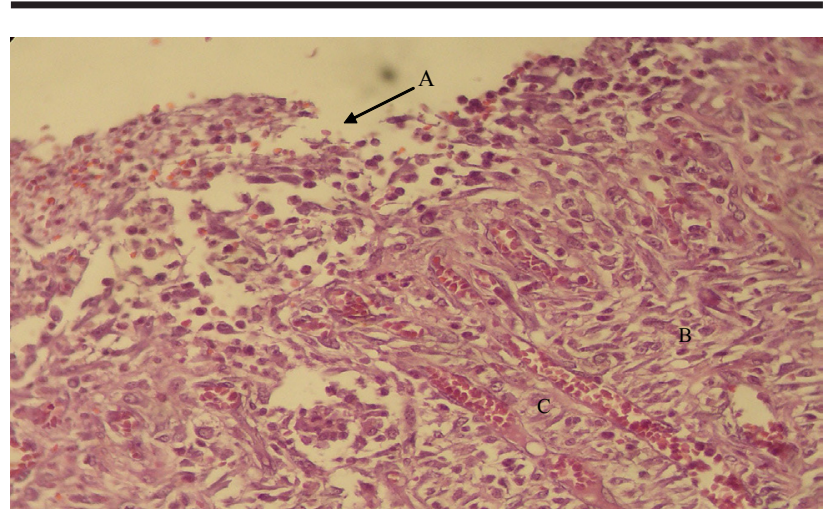

FIGURA 10 - Fotomicrografia do grupo controle do $7^{\circ}$ dia. Nota: Figura mostra a ausência de epitélio (A), presença de vasos dilatados (B) e de polimorfonucleares (C) (aumento de 40x). 


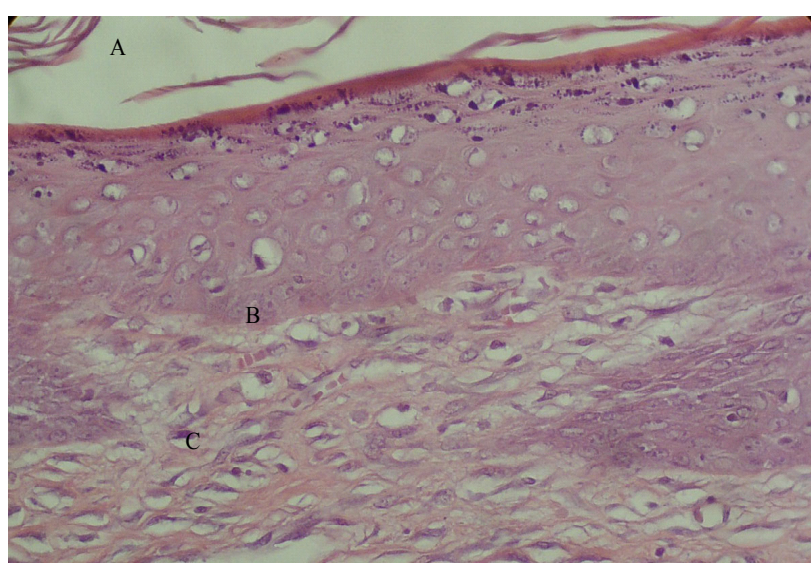

FIGURA 11 - Fotomicrografia do grupo experimento do $14^{\circ}$ dia. Nota: Epitelização parcial (A), moderada proliferação de fibroblastos (B) e formação de colágenos (C) (H-E com aumento de 40x).

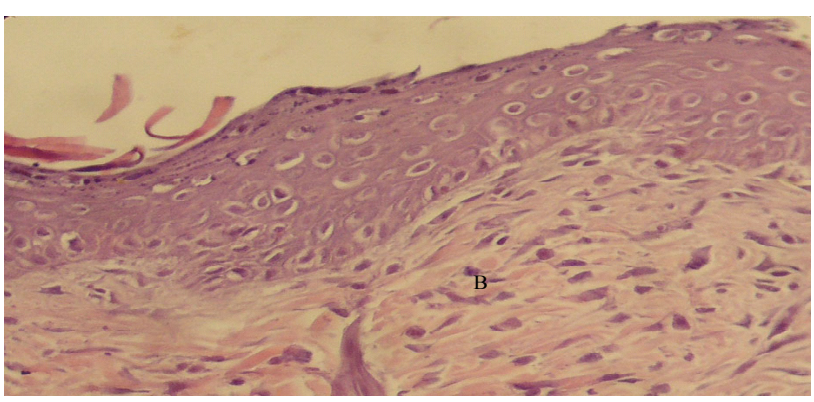

FIGURA 12 - Fotomicrografia do grupo controle do $14^{\circ}$ dia. Nota: Epitelização parcial (A), moderada proliferação de fibroblastos (B). (H-E com aumento de 40x).

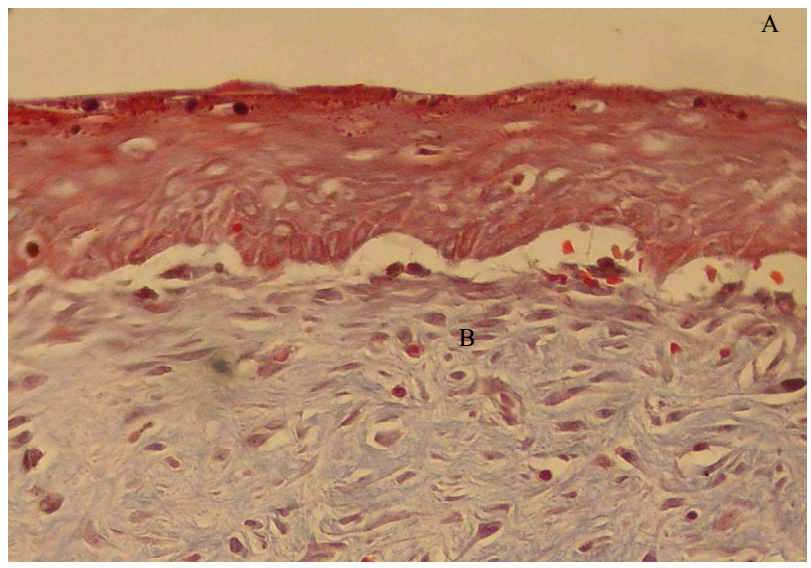

FIGURA 13 - Fotomicrografia do grupo experimento do $21^{\circ}$ dia. Nota: Reepitelização completa (A), intensa proliferação de fibroblastos (B) e grande quantidade de colágenos (C) (Tricômio de Masson com aumento de 40x)

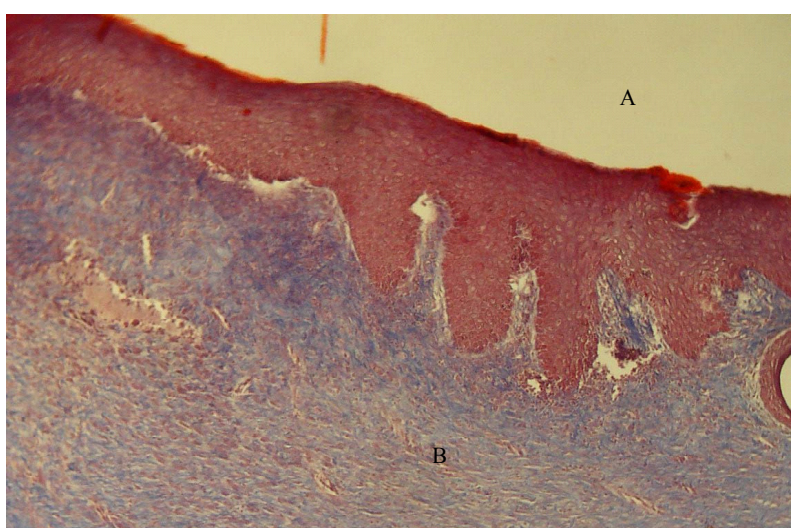

FIGURA 14 - Fotomicrografia do grupo controle do $21^{\circ}$ dia. Nota: Reepitelização completa (A) e grande quantidade de colágenos (B) (Tricômio de Masson com aumento de 40x)

\section{Discussão}

A Universidade Federal do Maranhão, tem um programa de fitoterapia coordenado pela prof a Terezinha Rego, que apresenta como principal meta, a valorização das plantas medicinais por meio de implantação de hortas comunitárias que têm oferecido medicina alternativa de elevado alcance social, principalmente para a população mais carente e com maior dificuldade de ser beneficiada pela medicina tradicional.

Fator que muito influi o uso do Babaçu, é a facilidade de obtenção, praticidade de manipulação, aplicabilidade nos animais, baixo custo e experiência no refino por parte dos funcionários da universidade.

Silva et al. ${ }^{12}$, utilizaram o extrato aquoso de Orbignya phalerata em estudo experimental e comprovaram sua eficácia como antiinflamatório.

Em outros trabalhos foi utilizado o extrato clorofórmico, porém a grande maioria em edemas induzidos por drogas. No caso deste estudo, o extrato aquoso é melhor em face de estar-se realizando estudo em feridas cutâneas abertas e de alguma forma o componente clorofórmico poderia interferir no resultado da pesquisa. Assim, não foi usado o extrato clorofórmico nem o alcoólico, pela possibilidade de ambos influírem no processo de cicatrização.

Aqui, neste trabalho, observou-se também que o extrato aquoso de Orbignya phalerata demonstrou atividade antiinflamatória por uso tópico na dose usada e não foi observada nenhuma reação adversa. Doses menores à aqui utilizada, mostraram-se ineficazes ${ }^{12}$.

A semelhança da técnica operatória utilizada por Miranda ${ }^{12}$, a ferida foi colocada no dorso do animal para que não houvesse interferência dele no mecanismo de cicatrização ${ }^{13,14}$.

A ferida operatória foi estudada por observações macro e microscópicas nos dias considerados mais significantes para o estudo do processo de reparação tecidual da pele dos ratos.

A determinação da área por softwares mostra-se eficiente porque faz a demarcação de todos os pontos da periferia da 
lesão, efetua os cálculos e depois os transforma em números decimais diminuindo as possibilidades de erro.

A escolha dos dias $7^{\circ}, 14^{\circ}$ e $21^{\circ}$ do pós-operatório, foi baseado no trabalho de Miranda ${ }^{8}$, que não observou alterações em relação a outros dias referidos por alguns pesquisadores. Ele observou que no $21^{\circ}$ dia de observação já há um completo fechamento da ferida, o que tornaria desnecessário o registro da área da lesão após esse período ${ }^{15,16}$.

Em relação à área da ferida, a análise de variância feita pelo teste da ANOVA, mostrou decréscimo significante ao longo do tempo tanto para o grupo experimento quanto para o grupo controle. Observa-se que as áreas foram significativamente menores no $14^{\circ}$ e $21^{\circ}$ dias. Ao comparar os dois grupos, nota-se que houve diferença significativa entre eles favorecendo o grupo experimento ${ }^{17,18}$.

Microscopicamente, verifica-se efeito significativo positivo na cicatrização do grupo experimento em relação ao controle no $7^{\circ}$ e $14^{\circ}$ dias, no que diz respeito à reepitelização ${ }^{19}$.

\section{Perspectivas}

A Orbignya phalerata (Babaçu) tem sido estudada e sobre ela existem muitos relatos na literatura ${ }^{20}$. O trabalho aqui apresentado comprova a eficácia como antiinflamatório tópico. No entanto, é necessário que outros ensaios sejam feitos no sentido de identificar a posologia e concentrações ideais. Como sugestão a estudos futuros, pode-se propor que sejam feitos com maior número de curativos diários; com doses variadas; concentrações aumentadas da droga por dose; procurar fracionar o extrato para se chegar ao elemento químico que tem ação terapêutica cicatrizante.

\section{Conclusão}

O uso tópico do extrato aquoso do mesocarpo de $\mathrm{Or}$ bignya phalerata (Babaçu) contribuiu positivamente para o processo de cicatrização, tanto no nível microscópico quanto no macroscópico das feridas cutâneas em ratos, principalmente no $7^{\circ}$ dia, onde a diferença em relação ao controle foi maior.

\section{Referências}

1. Araújo GF, Araújo FLSM, Torres OJM, Barros V. Ferida Operatória: Coberta ou Descoberta? Rev Bras Cir. 1987; 77:17-9.

2. Brito RMF. Avaliação da auto-reatividade induzida pelo tratamento com o Babaçu. [Monografia]. São Luis: Centro de Ciências Biológicas e da Saúde, Universidade Federal do Maranhão. 2001.

3. Corsi RCC, Corsi PR, Pirana S, Muraco FAE, Douglas J. Cicatrização das feridas. Revisão da literatura. Rev Bras Cir. 1994;84:17-24.

4. Felix VN, Yogi I. O organismo, a ferida e o processo de cicatrização. Rev Bras Med. 1990;47:355-60.

5. Joly AB. Botânica: Introdução à toxonomia Vegeral, 12.ed. São Paulo: Nacional, 1998.

6. MAIA MBS. Estudo da atividade antiinflamatória e outros efeitos farmacológicos de Orbignya phalerata. [Dissertação- Mestrado]. Fortaleza: Departamento de Fisiologia e Farmacologia. Universidade Federal do Ceará. 1987.

7. Mesquita LAF. Estudo da Cicatrização Cutânea Causada pelo Laser de CO2 Ultrapulsado em Retalho Dorsal de Ratos. [Dissertação- Mestrado] Curitiba: Faculdade Evangélica do Paraná, 2002.

8. Miranda LTGS. Uso da Tintura de Arnica em Feridas Cutâneas Abertas em Ratos. [Dissertação-Mestrado]. São Paulo: Programa de Pós-Graduação em Técnica Operatória e Cirurgia Experimental. Universidade Federal de São Paulo. 2001.

9. Oliveira AB. Espectrofotometria no controle de qualidade de fitoterápicos da Schinus terebinyhifolius raddi: uso de marcadores. [Dissertação -Mestrado]. São Luis: Centro de Ciências Biológicas e da Saúde, Universidade Federal do Maranhão. 2001.

10. Rego TJA. Fitogeografia das plantas medicinais no Maranhão. São Luis: EDUFMA. 1993.

11. Sanches-Neto R, Barone B, Teves DC, Simões MJ. Aspectos morfológicos e morfométricos da reparação tecidual de feridas cutâneas de ratos com e sem tratamento com solução de papaína a $2 \%$. Acta Cir. Bras. 1996; .8:.18-23.

12. Silva BP, Parente JP. An anti-inflamatory and immunomodulatory polysaccharide from Orbignya phalerata. Fitoterapia 2001;72;.887-93.

13. Silva CMP, Roch RM, Moreno JS. O Babaçu (Orbignya phalerata) como provável fator de risco de infecção humana pelo agente de cromoblastomicose no estado do Maranhão, Brasil. Rev Soc Bras Med Trop 1995;28: 49-52.

14. Vicentini RMR, Pinto-Neto AM, Lane E. Cicatrização do sítio cirúrgico incisional. Fisiologia, fisiopatologia e fatores de risco. Femina 1996;24:915-8.

15. Kuzu MA, Koskoy C, Kale T, Demiprence E, Renda N. Experimental study of the effect of preoperative 5fluorouracil on the integrity of colonic anastomoses. $\mathrm{Br}$ J Surg. 1998;85: 236-239.

16. Wendler LE. Estudo experimental comparativo da cicatrização de suturas jejunoileais em cães, utilizando o fio de poliglecaprone 25 [Tese - Doutorado]. Faculdade Evangélica de Medicina do Paraná; 1995.

17. Porcides RD. Estudo comparativo entre os fios de polipropileno e glicomer 60 na gastrorrafia em cães [Tese - Mestrado]. Faculdade Evangélica do Paraná; 2002.

18. Hermann JB; Woodward SC, Pulaski EJ. Healing of colonic anastomoses in the rat. Surg Gynecol Obstet. 1964;119: 269-275.

19. Jiborn H, Ahonen J, Zederfeldt B. Healing of experimental colonic anastomoses: The effect of suture technic on collagen concentratrations in the colonic wall. Am J Surg. 1978; 135:333-40.

20. Nomura LM. Estudo experimental comparative da cicatrização de sutura em ceco de ratos, utilizando os fios de polipropileno, poligrecapone 25 e glicomer 60 [Dissertação - Mestrado]. Instituto de Pesquisas Médicas, Faculdade Evangélica de Medicina; 1999. 


\section{Correspondência}

Antonio Gonçalves Filho

Av. dos Holandeses, Qd 29, ap. 302- Ponta D'areia - São Luis - MA

CEP: 650765-650

Tel:(98)3235-6440
Conflito de interesse: nenhum

Fonte de financiamento: Capes

Recebimento: 18/02/2005

Revisão: 04/06/2005

Aprovação: 11/06/2006

\section{Como citar este artigo}

Amorim E, Matias JEF, Coelho JCU, Campos ACL, Stahlke Jr HJ, Timi JRF, Rocha LCA, Moreira ATR, Rispoli DZ, Ferreira LM. AEfeito do uso tópico do extrato aquoso de Orbignya phalerata (Babaçu) na cicatrização de feridas cutâneas - estudo controlado em ratos. Acta Cir Bras. [periódico na Internet] 2006; Suppl 2:67-66. Disponível em URL: http://www. scielo.br/acb

Figuras coloridas disponíveis em $\underline{\text { http://www.scielo.br/acb }}$ 